\title{
Teacher Training and Skill Enhancement in India using Innovative Techniques
}

\author{
Seema Nair, Amruta Jog.
}

\begin{abstract}
In the present workforce, it is observed that most people are either unskilled or they find their jobs to be redundant or changing so rapidly that their skills become irrelevant. Earlier research suggests that the present-day education system is marksoriented, based mostly on rote learning, and does not train people with the skill sets required by the industry, thus creating a skill gap. Prior research points out that academicians and industry should work together to bridge this gap. In India, various initiatives have been undertaken by the Indian government, like "ITI Finishing Schools" which are implemented with the help of the Confederation of Indian Industry,or initiatives like "Skill India" and "Startup India", which focus on skill development.

Quality education and training are the strategic necessities that can deliver employment skills. As a part of skill enhancement, an employee should not only plan for the skills required for the automated world, but also acquire those that go beyond technical competence. Researchers observed that generic skills like creativity, innovation, imagination, decision making, analytical skills, and design skills will take up the priority spots on the employer's agenda. These skills have to be encouraged in the coming years and should be included in the course of formal education. To handle this daunting task, teachers have to anticipate and plan their activities, which would enhance their students' creativity. This asks for the skill development of teachers in the form of on-the-job training while performing regular teaching duties, which is a lifelong learning process.

It has been observed that the children educated through Finnish education system have been doing consistently well. Their skill anticipation and teacher training programs have been yielding good results. So, would it be possible to adapt their model to train teachers in India? If so, then how effectively? What changes need to be incorporated for implementing the same in Indian conditions? This research paper attempts to do a comparative study of education systems prevalent in Finland and India, with emphasis on teacher training and skill enhancement. In the process, also find ways for sustained development of prominent stake holders in education.The paper is based on analogies between Finnish education systems and Indian initiative towards quality education in the form of Draft National Education Policy 2019. The paper outlines the comparisons and possible changes in the Indian education system, based on the review of various literature available today. The conclusion is that, though Finnish education system cannot be adapted as it is in the Indian scenario but can definitely be implemented in certain areas which have been mentioned in the recommendations.
\end{abstract}

Keywords: Draft National Education Policy 2019, Finnish education system, teacher training program, skill enhancement of teachers.

\section{INTRODUCTION}

We believe that teaching is a noble profession. It is an opportunity to develop and educate an entire generation, thus helping in nation-building(teachertraining). Indian culture has always emphasized oneducation since ancient times. The Gurukul system, which is like the residential school nowadays, was a widely accepted method of imparting education in that era. This led to lecturing as the method of teaching and students memorizing the same later,which prevailed till recent times. The Indian education system has come a long way since then. But like every coin has two sides, the education system also has its advantages and disadvantages.

In India, in the pre-independence era, people from certain castes did not have access to basic education. So, the education system in India provides reservation for theunderprivileged. Also, free and compulsory education is provided to all children between the ages of 6 and 14 years by central and state governments. These schools also provide mid-day meals which have considerably reduced the number of dropouts. Moreover, the Government also provides free education for girls up to University level to encourage parents to educate the girl child. This has been a very tactful and successful initiative. Apart from these, scholarships are also made available to underprivileged but meritorious students. India also has an adult education program.

On the flip side, the evaluation pattern in the Indian education system emphasizes on scores rather than on quality education which encourages enrolment into coaching classes. This hampers student's creative skill which leads to boredom and students don't utilize the opportunity to learn. Students in higher classes,especially those in $10^{\text {th }}$ and $12^{\text {th }}$, have no time for extracurricular activities. In the course of completing education, students are forced to study subjects which they may not be interested in. Due to inappropriate student-teacher ratio, a'one size fits all' approach is adopted, which is not advisable. Parents decide the career path for their wards. They consider prestige and monetary benefits to decide the career. This leads to a flockapproach among parents and students. In a hurry to increase the number of educational institutes, poor quality educational institutes have mushroomed. But India has also given the world some of the best thinking minds.(educationsysteminindia)

The termeducation systemrefers to public schooling and more commonly to kindergarten through high school programs.(glossary, 2013) Draft National Education Policy of India has suggested numerous reforms and is a vivid step towards quality education in India(NEP2019) 
In education, the term professional development may be used for a wide variety of focusedtrainings, formal education, or highly developed professional learning intended to help administrators, teachers, and other educators enhance their professional understanding, competence, skill, and effectiveness.(glossary, 2013)

The teacher is the most crucial component in any education system. The teacher is mainly responsible for the execution of the educational process at any stage. This shows that it is very important to invest in the training of teachers which will lead to the nation's prosperity.

The National Council for Teacher Education has defined teacher education as - "A programme of education, research, and training of persons to teach from pre-primary to higher education level". (teachertraining)

Teacher education is a course that is connected with the development of teacher proficiency and skills that would enable and allow the teacher to meet the requirements of the profession and face the challenges in it.

Teacher education, according to Goods Dictionary of Education, means, - " all the formal and in-formal activities and experiences that help a person to be eligible to assume responsibilities of a conscious member of the educationvocation or to perform his tasks more efficiently. (teachereducation)

\section{HIGHLIGHTS OF THE DRAFT NATIONAL EDUCATION POLICY,2019}

The committee for Draft National Education Policy submitted itsreport on May $31^{\text {st }}$, 2019. The report recommends an education policy that effectively addresses the challenges of - access, equity, quality, affordability and accountability, confronted by the present education system.(Gayatri Mann, 2019)

National Education Policy 2019 has acknowledged the fact that children are not acquiring thebasic skills during their school education. Many children in grade V can neither read simple text nor do simple arithmetic calculations. Children lack the opportunity to enhance their innate skills. Various questions have been put forth to the experts and an inclusive report has been put forth. It is mentioned in the report that a lack of trained and qualified educators and not using best possible pedagogical skills, has been a foremost challenge. The policy focuses on building an excellent curricular and pedagogical framework, following the above guidelines.

The Draft Policy mentions the development of curriculum for early childhood education which consists of guidelines for up to3-year-old children (for parents and teachers) and educational outline for 3 to 8 -year-old children. This would be executed by refining Anganwadi and co-locating Anganwadi with primary schools.

- The school curriculum has been restructured in a new $5+3+3+4$ design conforming to the age ranges of 3 to 8 years, 8 to 11 years, 11 to 14 years and 14 to 18 years respectively.

5 years of Foundation stage consists of 3 years of preprimary along with grades 1 and 2

3 years of Preparatory (or later primary) stage consists of grades 3,4 , and 5

3 years of Middle (or upper primary) stage consists of grades 6,7 and 8
4 years of High (or secondary) stage consists of grades $9,10,11$ and 12 .

Depending on the age, the curriculum will incorporate ICT, discovery-based learning, building on playand pedagogy, slowly incorporating more aspects of textbooks and more formal class teaching.

Experiential learning in each subject, relations among different subjects, inculcating scientific temper, encouraging evidence-based reasoning, analytical, logical and quantitative thinking is emphasized more in the new policy. The committee proposes that the syllabus in each subject should be reduced to its crucial core content. This, in turn, would encourage holistic, as well as discussion and analysisbased learning.

It has been observed that class 10 and 12 board examinations place a vast amount of burden on students and encourage the harmful coaching culture. To avoid these harmful effects, the policy suggests that Board examinations should be restructured toboostholistic development, examinations should be conducted in a range of subjects, andit should test fundamental capacities which can be obtained by any student making the basic effort in the school class. The students can select their subjects and semester when they want to attempttheseboard exams.

The existing curriculumfollows a 'one size fits all' approach to education with little adaptability from student to student. The policy suggests the need to strongly support the student's ability.

To achieve this goal, the instructors i.e. teachers must be trained to implement appropriate models in line with the policy. It becomes imperative that students at each and every level of education are taught by passionate, inspired, highly competent, proficient and well-resourced teachers. The role of a teacher will be to guide students to streamline ideas and connect various contents of the article so that students themselves develop the skills of interpreting and analyzing complex information.

In India, there are very few initiatives that encourage bestperforming students or those who have a passion for teaching to take up this profession. Though written examinations like the TET (Teacher Eligibility Test) exist, they have hardly any correlation with teaching ability. The recruitment process does not assess motivation and passion.

There are almost 17,000 teacher education institutes in India, but according to Justice J.S Verma Commission (2012) formed by Supreme Court of India, a huge number of these institutes do not even attempt to provide quality education but on the contrary function as commercial establishments where degrees are available for a price.

To counter this, the policy aims that by 2030, the prerequisite qualification for teachers will be a four-year integrated B.Ed. degree which will include knowledge content, pedagogy, and effective practical training in the form of demonstration lessons in local schools.

The Draft Policy proposes that teachers should be employed with a particular school for at least 5 to 7 years. Further, teachers will not be allowed to partake in any non-teaching activities during school hours that could affect their teaching abilities. 
Due to these changes, the teaching profession will escalate in the reverence which will inspire the best students to enter this profession. The policy also has made provisions for continuous professional development. It recommends that teachers should invest a minimum of 50 hours for their professional development every year. (NEP2019)

\section{FINLAND EDUCATION}

Finland became an independent country in 1970. After 1970, Finland implemented a new education system. Authorities in Finland believed that education and health are the most important factors which will contribute towards the nation's growth. Taking this into consideration, Finland provides free education and free health services to every citizen and the expenses incurred are covered through the country's tax system.

The literature review covers a variety of related articles, and some official documents like national core curricula and Finnish Basic Education Act. The basic ethos of Finnish society is equity. Everyone gets needed support from the State irrespective of socio-economic, religious, ethnic background.(COUNCIL FOR CREATIVE EDUCATION, FINLAND)

The main objectives of the Finnish Education System are:

- To provide pupils with the knowledge and skills needed in life.

- To promote equality and civilization in society, and

- To provide adequate equity in education all through the country.

The important aspects of the Finnish System are:

- diversity and flexibilityrather than standardization.

- emphasis on extensive knowledge including all aspects of individual growth and learning, and

- culture of trust through professionalism.

(Finnish Education Act, 1998)

\section{COMPARISON}

- Finland is a small country in terms of its area and population, and skilled workforce of the country has to bear the brunt of every unskilled person. The idea behind free education for all, stems from this understanding - The burden of unskilled population on the country will be lesser when as many people as possible are well-educated and skilled. The decision to provide free education to all was definitely a bold one but proved to be a very effective and positive one in just few years. Government of India has implemented many initiatives in the field of education but with population of India being a major constraint, it may not be possible to provide free education at all levels.(esakal 18 july, 2019)

- $\quad$ Primary education is compulsory in Finland, and it is designed taking into consideration many subjects and skills. Thus, a person who wishes to change his/her field does not need to gain primary knowledge in that field all over again. Primary education is compulsory in India too. But a person who wishes to change his/her fieldhas to gain knowledge in the field, for example, a person who studied in the Science stream, but who now wishes to teach a language, would need to complete a formal degree course in the Arts stream.(esakal 18 july, 2019)

- Everything in basic education, including teachinglearning materials, health and welfare services, transportation (if necessary) and healthy lunch, is provided for students free of charge. Furthermore, any assistance for students who need special education is also completely free.(Ustun, Dec 31,2018).

In India, free and compulsory education is provided to all children between 6 and 14 years of age by the central and state Governments. Such school students are also provided mid-day meals at schools.

- Finnish educators focus on students with special needs, by spending more time and more educational resources on them. So, children who need extra support in learning are taken care of by people trained for it. Also, in the Finnish education system, there does not exist any selection procedure for students regarding entry into the basic education system. All schools have the same syllabus and all children are entitled to quality education.There is no selection procedure for basic education in schools; that is, students are not grouped into different schools based on their performance.Hence, local neighbourhood school is preferred. There is no national examination all throughthe ten-years of compulsory education in Finland (EDUFI, 2018).

In India, children with different levels of understanding and learning capacities find it difficult to cope upin class due to various reasons, but mainly due to the skewed student-teacher ratio. So, for not so educated or working parents, tuition classes are an easier option. Also, because of the importance or build-up around the $10^{\text {th }}$ and $12^{\text {th }}$ board exams, the tuition class business has boomed in India. Flock mentality is the side effect of this culture.

- Finnishbelievethat the emotional health of children is important, without which the students cannot learn in school. Therefore, in Finland, formal education starts at 7 years of age so that children spend time playing and forming emotional relations with their families and communities.

In India, basic education starts at the age of 3 years. This is based on indication from neuroscience which shows that over $85 \%$ of a child's cumulative brain development takes place before 6 years of age. So, this early start aims to promotehealthyand sustained brain development and growth.

- In Finland, children often have the same educator for the first six years. The educator gets to know each student well and can develop the learning experience 
which is suitable for their needs. The aim is that students enhance their thinking capacity and take responsibility for their learning. (Helsinki p. b., 2019) In India, this was the system followed earlier, for example, in the Gurukul. But now there is no literature to support this. Observation is that, in the first few years, though one teacher is responsible for all subjects, the teacher changes every year.

- PISA (Programme for International Student Assessment) is a global study by the OCED (Organisation for Economic Co-operation and Development). Every three years, it tests 15-year old students from all over the world in reading, mathematics, andscience. The tests are designed to measure how well the students havemastered important subjects so that they are prepared to face real situations in the adult world. Finland students have shown aboveaverage performance over the years according to OCED standards. The Finnish success in the PISA assessments is not based on standardized tests, but a more comprehensive vision of pupils' well-being and development.(OCED, 2018)

India has been a reluctant participant in PISA. India was a participant country in PISA in2009. However, students fared poorly then and secured $72^{\text {nd }}$ rank among 74 participants. Then, India did not participate. But India plans to participate in 2021.(financial express, 2018)

- Many other countries, including India, measure the achievement of their teachers by student performance and various grade methods. This may even result in teachers being fired if the pupils do not reach a certain level. This indicates a type of thought that only the results matter, not the teacher training. The quality of teachers seems to be the most prominent factor in the Finnish system.(FTTS.mov, 2011)

In India, due to the high demand for teachers and the easy availability of degrees, the quality of teachers has drastically fallen.

- Finland had made a political decision that education must be equal, and in the 1970s the country developed an inclusive school system that is common to all. Around this time, it was also decided that teachers must be trained in master's level university programmes. Finland's success was built mostly on these conclusions. Autonomy is one of the reasons why Finnish teacher training is considered so striking. (helsinki, 2019)

- Teachers are not allotted non-educational duties in Finland.(COUNCIL FOR CREATIVE EDUCATION, FINLAND) In India, teachers also have to manage noneducational duties like census, election, etc. along with their regular teaching duties. Lack of an educated, skilled workforce might be a reason for this.

Teacher training is an indispensable part of this mammoth task of enhancing the quality of education.
So, discussing teacher training in Finland and India is inevitable.

\section{THE FOLLOWING ARE THE CHARACTERISTICS OF TEACHER TRAINING IN FINLAND}

- The teacher training school is a part of the Faculty of Educational Sciences and works in close collaboration with scholars at the university. The school has four tasks: basic education, teacher traineeship, partaking in research and further education for teachers.(educationsciences)

- All teachers must hold a Master's degree and initial teacher training includespractice in teaching. The teaching occupation is highly esteemed and admired in Finland, which makes it possible to select the best young studentsas teachers. A teacher is an expert, equivalent to an engineer, lawyer or a medical doctor. Teachers have an autonomous position in their work with high self-dignity.

- Toestablish as a competent teacher in Finland, university students practice in a teacher training school during their course. The Master's Degree includes 20 credits of training for both class teachers and subject teachers. Finnish teachers consider in-service training to be a privilege and therefore participate actively.

- The teacher training schools in Finland are researchbased. On a global level, it is not often that a country trains teacher at universities that also engage in highquality research. Teacher trainees at Finnish universities complete a final thesis with the same necessities asin all otherstreams. Here, teachers are developed as researchers. Action research is the baseline for the teaching profession. So, they need to be told what to do, but they know what is expected out of them.(COUNCIL FOR CREATIVE EDUCATION, FINLAND)

- In many countries, a teacher trainee would be sedentaryand perceiving the work of other teacher from the back of the class. But not in Finland. The teacher apprentices are engaged and work hands-on from day one. The profession is demanding, and, at times, it can be very intense. A trainee teacher has to use a lot of own judgment and understanding. A teacher should be able to judge when to hand over a pupil to other experts, for example speech therapists or psychologists.(Helsinki U. o., 12 Apr 2019)

- Even though the teacher training period, in both lectures in class and subject teacher training, is only 20 credits out of the 300-credit Master's degree, it is meaningful and significant for the apprentices. The directed teacher training periods offer each student an opportunity to try out in practice allthat they have learned during their studies. Paramount in teacher training is combining theory and practice. The teaching and guidance staff in day-care centres generally have Bachelor's degrees.(university, 2019) 
- The education and training that teachers undergo is important role in the Finnish education system. Every teacher completes a 5-year course, which leads to deep knowledge of the subjects that they later teach, along with the development of a scientific viewpoint. Since only about $10 \%$ of the teachers pass the eligibility test, it ensures that thebest teachers are chosen. Such a teacher, who has proven his /her mettle through so many criteria, can take even the toughest decisions for students' development with ease.(esakal 14 Feb, 2019)

- In Finland, it is believed that teachers with a master's degree are instilled with a yearning to continuously develop the school system and their skills, as well as to come up with solutions to local problems.

- Finland's student-centred tactic also includes teacher autonomy. Teachers are free to plan their lessons malleably, as essential for the individual requirements of their students. There, teachers are involved in chalking out the curriculum and creating learning materials.

- In addition to professionally trained teachers, Finnish success in education is based on equal opportunity.

\section{TEACHER TRAINING IN INDIA}

- India has made significant growth in education since independence with respect to literacy, infrastructure, worldwide access and enrolment in schools. (concept of teacher education, n.d.)

- Education in India is provided by public and private sectors.

- Teacher training courses in India are

Certificate
Diploma
Bachelor's Degree
Master's Degree
Doctorate

- Each course is a combination of theory and practical training.

- Courses have been designed at each level of education. An aspiring candidate can opt forcourses at different levels like elementary level teacher, nursery teacher or primary level teacher.

- Based on personal preference, one may select a good subject and go for the four-yearintegrated B.Ed. course.

- After finishing the above stated program, a candidate may go for further studies or attempt the CTET (Central Teacher Eligibility Test). Clearing the CTET will help a candidate to become a teacher in schools under the Central Government (example- KendriyaVidyalayas). A candidate may also attempt for state wise TET and work as a teacher in State Government-run schools.(Teacher training india)

- Teacher education in India can be divided broadly as:

- pre-service education which trains students for a career in education as mentioned above. With the earlier pattern of curriculum and Programme structure, NCERT and Varma commission (2012) had been critical about the programme with the opinion that the programme offers the teachers with basic skills and expects that they will be able to apply their learning to any context. But, after training, when a teacher takes up a job and enters classroom, she realises that her students are at different academic levels. First generation learners, high absenteeism, socio- economic circumstances, lack of nutrition etc. are some of the contributors to this problem. She is mostly lost on how to achieve optimum learning in such situation. NCERT and Varma commission (2012) were also of the opinion that the curriculum failed to address the psychological aspect. This will change with the integrated B.Ed. course included in Draft National Educational Policy 2019.

- In-service training provided by the Government, SSA(Sarva Shiksha Abhiyan) or NGOs and public initiatives. Despite the SSA allotting $64 \%$ of funds for teachers, teacher performance has not meaningfully enhanced emphasizing the need to improve the format and strategy of inservice teacher training. (Samhita, 2016)

\section{RESULT AND DISCUSSION}

Education is the keyto renovating a developing country. Now that India is on the verge of implementing the new Education Policy, it is the right time to make a few changes. The iron is hot, and a few correct blows might work wonders in shaping the next generation, the nation builders. Due to various constraints, it will not be possible to completely adopt an entire Finnishmodel. But it is possible to adopt some parts of the model. In recent years, more and more children in developing nations have increased access to education. Unfortunately, as proved by worldwide comparative studies, the standard of teaching has not always been up to the mark.

Teacher training is an important factor. The experts from various departments - education, research, psychology, etc. can come together and develop a comprehensive guide for educating students of the teachers' training school. For teachers already in the system, skill enhancement must be different from content enrichment. A four-year integrated B.Ed. course is a very welcome move. This will ensure that only the ones with a genuine interest in the teaching profession will pursue the course.

\section{RECOMMENDATIONS}

- The same teacher for the first few years of school education will help in evaluating the comprehensive growth of the pupil without undue stress of examinations on the teacher as well as on the child. The teacher can also do justice to the innate skills of the child. The teacher will not be under pressure to finish the syllabus in the stipulated time so that the next teacher can take the baton.

- Instead of firm discipline and examinations testing rote learning, we can approach education in a studentcentred way. 
- It would be advisable to make 'Teaching' a highly respected profession with a good remuneration so that the best young students choose this profession. The temporary status of teacher employment has done more bad than good.

- Senior teachers could guide the junior teachers to carry the country's and institution's vision forward. The atmosphere should beone of co-operation rather than competition, even among departments.

- The role of the guiding teacher at the teacher training school is of great importance because it allows the student to reflect upon her/hisprogress. The main idea behind teacher training practices is to help the students develop as teachers in many ways.

- A teacher should be able to enhance her/hisstudent's passion to learn, encourage a spirit of equality in school and achieve positive learning results.

- A teacher should be able to work in close association with academiciansand researchers from various departmentsat the university.

- Teachers should work together to make sure that theirstudents get the best possible education. They should get involved in projects which can generate change and be aware of different ideas in the education field. They should be provided this opportunity through faculty development programmes.

- Teachers should be trained in such a way that the desire to incessantly develop their skillsgets imbibed into them.

- With a master's degree and a research-oriented mind, a teachermay also come up with solutions to local problems as was the case during ancient times in India. 'Guru' used to be a guiding torch for society at large.

- All long-distance B.Ed. courses must be monitored, and if possible curbed.

- From being teacher centric with a fixed pattern, education should be learner centric with flexible pattern. Students should be made responsible for their own knowledge upliftment.

- A teacher cannot stop learning. An educator must realise that learning is a continuous evolving process and upgrading should come naturally as the individual's responsibility.

Teachers should print practices and research conducted so that the fraternity can work together with a co-

- operation.

\section{REFERENCES}

1. (n.d.). Retrieved from https://www.apnaahangout.com/teachertraining -courses/

2. (n.d.). Retrieved from https://surejob.in/10-fundamental-problemswith-education-system-in -india.html

3. (n.d.). Retrieved from https://mhrd.gov.in

4. (n.d.). Retrieved from Faculty of Educational Sciences,

5. (n.d.). Retrieved http://archive.mu.ac.in/myweb_test/ma\%20edu/Teacher\%20Educatio n\%20-\%20IV.pdf

6. (2018). Retrieved from oced.org

7. concept of teacher education. (n.d.). Retrieved from archive: http://archive.mu.ac.in/myweb_test/ma\%20edu/Teacher\%20Educatio n\%20-\%20IV.pdf

8. COUNCIL FOR CREATIVE EDUCATION, FINLAND. (n.d.) Retrieved from https://www.ccefinland.org/finland-education-modelclyvm

9. esakal 14 Feb. (2019, february 14). Retrieved from www.esakal.com

10. esakal 18 july. (2019, july 18). Retrieved from www.esakal.com
11. esakal 18 july. (2019, july 18). Retrieved from www.esakal.com

12. financial express. (2018, september 11). Retrieved from https://www.financialexpress.com/education-2 what-is-pisa-test-indiais-taking-part-first-time-since-2009-chech-questions-rankings-scoressubject/1309185/

13. Finnish Education Act. (1998). Retrieved from http://ncee.org/2017/01/finland-basic-education-act-1998/

14. FTTS.mov. (2011, may 12). Retrieved from https://youtu.be/vUMrMSGiym4

15. Gayatri Mann, A. V. (2019, october). Draft National Education Policy 2019. IIMM, pp. 35-39.

16. glossary. (2013). Retrieved from https://www.edglossary.org/education-system/

17. helsinki. (2019) Retrieved https://www.helsinki.fi/en/news/teaching-studying-at-theuniversity/jari-lavonen-the-finnish-education-system-cannot-becopied-but-parts-of-it-can-be-exported

18. Helsinki, p. b. (2019, february 14). infofinland. Retrieved from infofinland.fi

19. Helsinki, U. o. (Director). (12 Apr 2019). Why is Finnish Teacher Education excellent? [Motion Picture].

20. OCED. (2018). Retrieved from oced.org

21. Samhita. (2016, April 22). The parody that is teacher education in India. Retrieved from http://www.forbesindia.com/blog/economypolicy/the-parody-that-is -teacher-education-in-india/

22. Teacher training india. (n.d.). Retrieved from ncte/india.org/NCTEACT

23. university, h. (2019, Apr). Retrieved from https://www.helsinki.fi/en/news/education-news/why-is-finnishteacher-education-excellent-teacher-training-schools-provide-oneexplanation

24. Ustun, U.-0.-9.-6. A.-0.-2.-6. (Dec 31,2018). Analysis of Finnish Education System to question the reasons behind Finnish success in PISA. Studies in Educational Research and Development, 93-114. Retrieved from https://files.eric.ed.gov/fulltext/ED591431.pdf

\section{AUTHORS' PROFILES}

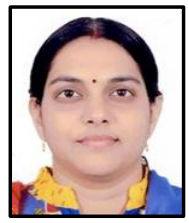

Mrs. Seema Nair is teaching at BMCC since past 5 years. She is a faculty for Business Mathematics, Business Statistics and Research Methodology. She has completed Faculty Development Programmes in Probability and Statistics and Software $\mathrm{R}$ with NPTEL (National Programme on Technology Enhanced Learning)

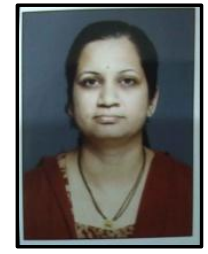

Mrs. Amruta Jog is teaching at BMCC, Pune for 11 years now. Having a teaching experience of over 20 years, she has taught $\mathrm{C}$ programming, C++, Data Structures, RDBMS, Operating System and Software Testing to students in various institutes in Pune. She actively participates in various national level conferences, having presented 3 review papers till now. She has also recorded educational video lectures for EMRC (Educational Multimedia Research Centre) at Savitribai Phule Pune University. She has completed Faculty Development Programme in (Internet of Things) with NPTEL (National Programme on Technology Enhanced Learning). She has also completed a certificate course on Cloud computing with NPTEL.She has co-authored and published a book on $\mathrm{C}$ programming. 